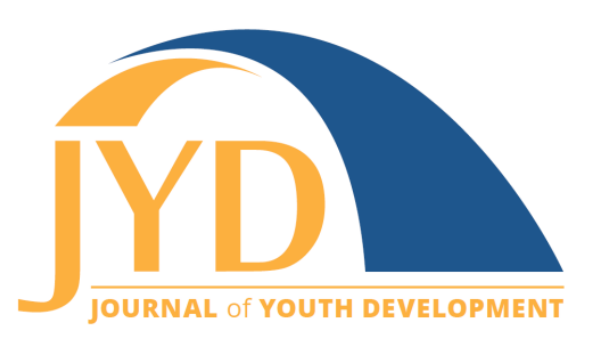

http://jyd.pitt.edu/ | Vol. 16 Issue 5 DOI 10.5195/jyd.2021.1190 | ISSN 2325-4017 (online)

\title{
Journal of Youth Development's Stance on Diversity, Equity, Inclusion, and Access
}

\section{Kathrin C. Walker}

University of Minnesota Extension

kcwalker@umn.edu

\begin{abstract}
The Journal of Youth Development is committed to furthering diversity, equity, inclusion, and access in scholarly publishing. This Editor's Note provides an overview of our ongoing resolve and collaborative process to review and shape policies and procedures to enhance our contributions to recognizing, valuing, and promoting racial equity, inclusion, and social justice.
\end{abstract}

Key words: diversity, equity, inclusion, access, anti-racism, bias, publishing

The Journal of Youth Development (JYD) is an applied journal, rooted in bridging youth development research and practice. At our core is our commitment to valuing the diversity of youth, youth workers, and researchers that are dedicated to inclusive, equitable youth development approaches and positive outcomes for all youth. However, we recognize that the field of youth development lacks diversity, equity, inclusion, and access in far too many key areas. JYD is committed to making a difference and we have begun developing strategies to make our publication submission and selection processes inclusive, accessible, and equitable.

\section{Context}

We live in a time filled with political turmoil, health and economic uncertainty, shifts in roles and responsibilities of families, schools, and programs, and increasing racial unrest. As a result, the United States has begun to reflect on how to use these moments-specifically the death of George Floyd-to address inequities due to historical racism and various forms of ongoing bias and discrimination. As a society, many have come to realize that racism and other structural barriers to opportunity have created underlying social, economic, and health conditions that

(cc) EY New articles in this journal are licensed under a Creative Commons Attribution 4.0 License. This journal is published by the University Library System, University of Pittsburgh and is cosponsored by the University of Pittsburgh Press. The Journal of Youth Development is the official peer-reviewed publication of the National Association of Extension 4-H Youth Development Professionals and the National AfterSchool Association. 
have left youth of color, especially Black youth, facing disproportionate and unfair risks and, in some cases, death. These current realities reflect centuries of inequity due to discrimination and racism inflicted upon Black communities and actively promoted and too easily tolerated by dominant White society. What does this all mean for the field of youth development, and for this journal that serves to advance it?

On May 25, 2020, 17-year-old Darnella Frazier-a Black girl on her way to the corner store to buy snacks with her 9-year-old cousin-courageously filmed the murder of George Floyd by a White police officer. She was given an honorary Pulitzer Prize for her video that helped disprove the police narrative, create momentum for accountability, facilitate the trial's historic outcome, and catalyze a global racial justice movement. Young people have been at the forefront of social justice throughout history. Could this historic moment be a spark to ignite our collective response as youth development advocates?

Still reeling a week later, the JYD Publications Committee met. In those early days, we were all inundated with perfunctory thoughts-and-prayers statements from every possible organization. There was strong support from the almost all White committee for JYD to take a stand. As JYD's editor, I firmly felt that instead of a statement of support, JYD should offer a commentary to speak squarely to racial injustice and youth work with a concrete call to action for those in the field and for the journal itself.

We must leverage this critical moment to center the lives and value of all young people and to boldly challenge the status quo in how we understand and support them. The power of racism as a structuring ideology within society-within youth work, within publishing-lies in its ability to reimagine itself in new moments and contexts. This editorial shares our ongoing resolve and collaborative process to both reflect and pursue bold action beyond rhetoric and performance as we stand in solidarity with the communities we study and serve to ensure that all young people thrive.

\section{Call to Action}

Corliss Outley and Dale Blyth (2020) put forth a commentary that outlines the need to promote a strong and sustained commitment to antiracist approaches to research, practice, and policy in the youth development field. "As a journal and a representative of our larger field, we must condemn racism in all of its many forms and acknowledge the impact that historic, deeply rooted, and systemic inequities have on our youth, our youth workers, and our scholars as well as our institutions and organizations (Outley \& Blyth, 2020, p. 2). Specifically, they call upon our 
fields' journals to strengthen our antiracism efforts by (a) diversifying our editorial boards, (b) ensuring fairness in all journal processes, and (c) highlighting content that documents the impact of racism on youth development.

\section{Equity Task Force}

With the commentary as our lighthouse, JYD's publications committee assembled an Equity Task Force to review and shape JYD policies and procedures to enhance our contributions to promoting racial equity, inclusion, and social justice. The task force was composed of JYD editors, publications committee members, reviewers, authors, and those committed to social justice and antiracism (see Appendix). We intentionally included members who are from historically excluded groups, and in different career stages and roles. We are grateful for their time, perspectives, and insights.

The task force identified four priority areas and created subgroups to discover issues and develop recommendations (some from Roberts et al., 2020) for JYD:

1. Mission: the ways our mission and goals might be adjusted to best reflect our values and the importance of equity in our field.

2. Leadership: the diversity of our leadership groups and how people are selected to ensure inclusivity.

3. Expectations: the ways we seek manuscripts and set clear expectations for how authors address equity, race, and diversity.

4. Operations: the criteria and ways we review and edit submissions.

The full task force and each subgroup met from January through May 2021 and submitted recommendations to the publications committee in June 2021.

\section{Proclaiming Our Stance}

The publications committee and editorial team co-created and publicly proclaim the following vision, mission, and values for this journal:

We, the journal editors and members of the JYD Publications Committee, have worked together to create a new vision and mission statement and a set of values and recommendations to more fully reflect the importance of diversity, equity, inclusion, social justice, and an anti-racist approach to researching, understanding, publishing, and practicing quality youth development. These efforts are not intended to narrow the types of manuscripts we seek but rather 
JYD's Stance on Diversity, Equity, and Inclusion

to ensure that all perspectives are welcome, reviewed appropriately, and published in ways that advance the field, enhance bridging between research and practice, encourage diverse voices, and ensure equity for all youth, their families, and their communities.

Our vision is a world in which all youth and communities are authentically represented in youth development scholarship and practice, and in which youth development scholarship contributes to repairing historical and current inequities.

Our mission is to bridge research and practice by cultivating and publishing youth development scholarship with and for youth, practitioners, and researchers in pursuit of an equitable and just society in which all young people can thrive.

We value

- the dignity, humanity, and value of every young person

- strengths-based approaches that lift up assets of individuals and communities

- human rights and equitable opportunities for all through the promotion of antiracist and social justice approaches, including racial, gender, and economic justice

- diverse scientific and systematic approaches to knowing and making meaning

- wisdom and knowledge gained through practice and experience

- critical understanding of historical and current intersecting systems of oppression

- different types of scholarship, including the scholarship of

- discovery

- integration including synthesis across disciplinary perspectives

- application and engagement

- teaching and learning processes

- working in partnership with and on behalf of practitioners and researchers and the diverse youth and families they serve and study

- partnership approaches that equitably involve practitioners, researchers, youth, families, and cultural perspectives

- expanding the authentic understanding of youth and their contexts as part of youth development scholarship 
JYD's Stance on Diversity, Equity, and Inclusion

- constructive and critical discourse across diverse perspectives in order to enhance and advance youth development approaches, programs, and theory

- open access for all authors and all users

\section{Charting Our Course}

Efforts to promote diversity, equity, inclusion, and access and to address disparities are underway at all leadership levels. We have solicited a systemic review of past JYD articles from a diversity lens, and we aim to update our guidance for authors, examine our peerreview processes for potential bias, and track progress on diversity goals. The task force relied heavily on the strategies put forth by Buchanan et al. (in press), and each subcommittee offered the following recommendations.

\section{Leadership}

Recommendations and strategies for leadership on equity focus on four levels: publications committee, editor, section editors, and reviewers:

- We have established a standing Diversity, Equity, Inclusion and Access (DEIA) Committee to oversee JYD's commitments to build a more diverse and inclusive publications committee, track and report DEIA data, and establish onboarding processes with DEI guidance.

- Our editor-in-chief is to take a position on DEIA through editorials (like this one) and other channels, ensure accountability of DEIA progress, and represent the journal commitment to DEIA with its co-sponsoring associations.

- At the section editor level, the aim is to produce a briefing document on unconscious bias in the review process, solicit submissions by members of under-represented groups, prioritize or reserve space for manuscripts that focus on DEIA efforts, encourage authors to cite those from under-represented groups, and develop an accountability system to examine the diversity of reviewers.

- At the reviewer level, we want to explore alternative strategies like panel or group reviewing as well as incentives and recognition for reviewers. We want to expand the reviewer pool through mentoring junior reviewers, recruiting a more diverse reviewer pool, and training practitioner reviewers. 


\section{Expectations and Operations}

We were pleased to discover and will draw upon the Recommendations and Diversity Accountability Index (Buchanan et al., in press) to ensure equity in how research is conducted, reported, reviewed, and disseminated. For example, we will develop review criteria to incentivize and assess diversity of samples. Articles should report and justify the diversity of their sample, make clear the extent to which findings generalize across populations, and make transparent how author identities relate to the topic and/or participants. Adding this expectation does not mean that each submission must have a diverse sample, but rather that the authors need to acknowledge and be explicit about any limitations.

\section{Expanding Our Perspectives}

We cannot do this work without you, our readers, reviewers and contributing authors. We encourage you to read and share our articles. For example, in this issue alone I would highlight "Silence is Not an Option: Oral History of the Study of Race in Youth Development Through the Words of Esteemed Black Scholars" (Harris \& Outley), "Sociopolitical Participation Among Marginalized Youth: Do Political Identification and Ideology Matter?" (Marchand), "The Complexities of Student Engagement for Racially Minoritized Youth in an After-School Program" (Sjogren \& Melton), "Increasing Latinx Youth Engagement Across Different Types of AfterSchool Organizations" (Moncloa et al.), and "Examining the Knowledge, Skills, and Dispositions of 4-H Professionals Related to LGBTQ+ Youth" (Gonzalez).

Recent publications address indigenous identity (Farella et al., 2021), LGBTQ+ inclusion (Rand et al., 2021), critical consciousness (Gonzalez et al., 2020), Black family engagement (Case, 2020), the Thrive model though an equity lens (Fields, 2020), Latinx adolescents' peer ethnic discrimination (Ma et al., 2020) countering fascism (Arbeit et al., 2020), Black families' reactions to socialization interventions (Anderson et al., 2020) and leading with youth of color (Clemons, 2020).

Next, we invite you to work with us as we explore and enhance the peer-review process. We want to grow our reviewer pool to reflect the diversity of the field. Enroll as a reviewer and indicate your interest areas. As the online platform is upgraded, we will be working to strengthen how reviewers can share their background and expertise to be best matched with manuscripts. Then as a reviewer, ask difficult questions, offer concrete and constructive feedback, and challenge authors to discuss generalizability, implications, and limitations. 
Journal of Youth Development | http://jyd.pitt.edu/ | Vol. 16 Issue 5 DOI 10.5195/jyd.2021.1190

JYD's Stance on Diversity, Equity, and Inclusion

Finally, as contributing authors, we ask you to trust us with your manuscripts and help us address diversity concerns. For example, report and justify the diversity of your sample, make clear the extent to which your findings generalize across populations, make transparent how author identities relate to the topic and/or participants, and suggest potential reviewers with your submission to help us diversify our reviewer pool.

We are determined to meet this moment and make JYD's publication submission and selection processes inclusive, accessible, and equitable.

\section{References}

Arbeit, M. R., Burnham, S. L. F., de Four, D., \& Cronk, H. (2020). Youth practitioners can counter fascism: What we know and what we need. Journal of Youth Development, 15(5), 37-67. (https://doi.org/10.5195/jyd.2020.936)

Anderson, R. E., Metzger, I., Applewhite, K., Sawyer, B., Jackson, W., Flores, S., Majors, A., McKenny, M. C., \& Carter, R. (2020). Hands up, now what?: Black families' reactions to racial socialization interventions. Journal of Youth Development, 15(5), 93-109. (https://doi.org/10.5195/jyd.2020.887)

Buchanan, N. T., Perez, M., Prinstein, M., \& Thurston, I. (in press). Upending racism in psychological science: Strategies to change how our science is conducted, reported, reviewed, and disseminated [Manuscript submitted for publication]. (https://psyarxiv.com/6nk4x/)

Case, A. S. (2020). "Doing our part": What motivates black family engagement in an after-school program. Journal of Youth Development, 15(6), 44-69. (https://doi.org/10.5195/jyd.2020.887)

Clemons, R. L. F. (2020). Leading with youth of color: Organizing for educational change. Journal of Youth Development, 15(5), 110-125. (https://doi.org/10.5195/jyd.2020.785)

Farella, J., Moore, J., Arias, J., \& Elliott-Engel, J. (2021). Framing indigenous identity inclusion in positive youth development: Proclaimed ignorance, partial vacuum, and the Peoplehood Model. Journal of Youth Development, 16(4), 171-194. (https://doi.org/10.5195/jyd.2021.1059)

Fields, N. I. (2020). Exploring the 4-H Thriving Model: A commentary through an equity lens. Journal of Youth Development, 15(6), 171-194. (https://doi.org/10.5195/jyd.2020.1058)

Gonzalez, M., Barker, A., Clarke, M., \& Byrd, C. M. (2021). Examining the knowledge, skills, and dispositions of 4-H professionals related to LGBTQ+ youth. Journal of Youth Development, 16(5), 193-211. (https://doi.org/10.5195/jyd.2021.1096)

Gonzalez, M., Kokozos, M., Byrd, C. M., \& McKee, K. E. (2020). Critical positive youth development: A framework for centering critical consciousness. Journal of Youth Development, 15(6), 24-43. (https://doi.org/10.5195/jyd.2020.859) 
Journal of Youth Development | http://jyd.pitt.edu/ | Vol. 16 Issue 5 DOI 10.5195/jyd.2021.1190 JYD's Stance on Diversity, Equity, and Inclusion

Harris, K. L., \& Outley, C. (2021). Silence is not an option: Oral history of race in youth development through the words of esteemed Black scholars. Journal of Youth Development, 16(5), 9-40. (https://doi.org/10.5195/jyd.2021.1091)

Ma, T.-L., Yu, M. V. B., Soto-Lara, S., \& Simpkins, S. D. (2020). Latinx adolescents' peer ethnic discrimination in after-school activities and activity experiences. Journal of Youth Development, 15(6), 195-221. (https://doi.org/10.5195/jyd.2020.938)

Marchand, A. D., Frisby, M., Kraemer, M. R., Mathews, C. J., Diemer, M. A., \& Voight, A. M., (2021). Sociopolitical participation among marginalized youth: Do political identification and ideology matter? Journal of Youth Development, 16(5), 41-63. (https://doi.org/10.5195/jyd.2021.1089)

Moncloa, F., Erbstein, N., \& Subramaniam, A. (2021). Increasing Latinx youth engagement across different types of after-school organizations. Journal of Youth Development, 16(5), 140-156. (https://doi.org/10.5195/jyd.2021.1084)

Outley, C. W., \& Blyth, D. A. (2020). Race, anti-racism, and youth development: From awareness to sustained action. Journal of Youth Development, 15(5), 1-15. (https://doi.org/10.5195/jyd.2020.1005)

Rand, J. J., Paceley, M. S., Fish, J. N., \& Anderson, S. O. (2021). LGBTQ+ inclusion and support: An analysis of challenges and opportunities within 4-H. Journal of Youth Development, 16(4), 26-51. (https://doi.org/10.5195/jyd.2021.1072)

Roberts S. O., Bareket-Shavit C., Dollins F. A., Goldie P. D., Mortenson E. (2020). Racial inequality in psychological research: Trends of the past and recommendations for the future. Perspectives on Psychological Science, 15(6), 1295-1309. (https://doi.org/10.1177/1745691620927709)

Sjogren, A. L., \& Melton, T. N. (2021). The complexities of student engagement for historically marginalized youth in an after-school program. Journal of Youth Development, 16(5), 105-121. (https://doi.org/10.5195/jyd.2021.1068) 